\title{
Diagnóstico e zoneamento geoambiental da APA da Bacia Hidrográfica do Rio Machado-MG
}

\section{Geoenvironmental analysis and zoning of the APA of Hydrographic Basin of Machado River}

\author{
Clibson Alves dos Santos \\ Professor Associado I - Instituto de Ciências da Natureza - UNIFAL \\ clibsonsantos@gmail.com
}

\section{Resumo}

A Área de Proteção Ambiental (APA) da Bacia hidrográfica do Rio Machado (APA-BHRM) localizada no Sul de Minas Gerais foi criada em 1999. Em 2015 após a criação do conselho gestor, estabeleceu-se uma parceria técnico-científica entre IEF - Sul de Minas, UNIFAL-MG e a ARPA Rio Grande - Agência Regional de Proteção Ambiental da Bacia do Rio Grande para a elaboração do diagnóstico e zoneamento geoambiental da APA tendo como base a análise integrada de estudos temáticos sobre hidrografia, aspectos climáticos, geologia e solos, geomorfologia e processos erosivos, uso e ocupação da terra e cobertura vegetal, análise demográfica e socioeconômica e levantamento da fauna e flora. Além dos documentos citados, produziu-se um material didático voltado para professores utilizarem o contexto ambiental da região para o ensino de Geografia e Ciências na educação básica. As análises mencionadas acima, resultaram na proposição de um zoneamento geoambiental, indicando cinco zonas segundo as suas peculiaridades naturais, tendo como critérios fundamentais a cobertura vegetal/uso dos terrenos, os solos, as rochas e o relevo, sendo elas: Zona Proteção Ambiental (ZPA), Zona de Interesse Ecológico (ZIE), Zona de Interesse Hidrológico (ZIH), Zona Restrição Produtiva 1 (ZRP 1) e a Zona de Adequação Produtiva 2 (ZAP 2). O zoneamento proposto conjuntamente com os estudos temáticos realizados, visam subsidiar estudos subsequentes e auxiliar nas discussões e tomada de decisões sobre a gestão ambiental sustentável no âmbito do conselho APA-BHRM e das demais entidades que atuam na unidade. Além disso, espera-se que este estudo seja uma das bases para a complementação futura dos estudos relacionados ao plano de manejo.

Palavras-chave: zoneamento geoambiental, área de preservação permanente, plano de manejo

\begin{abstract}
The Environmental Protection Area (APA) of the Machado River Basin (APA-BHRM) located in the south of Minas Gerais was created in 1999. In 2015 after the creation of the management council, a technical-scientific partnership was established between IEF - South of Minas, UNIFAL-MG and ARPA Rio Grande - Regional Environmental Protection Agency of the Rio Grande Basin for the elaboration of the APA geo-environmental diagnosis and zoning based on the integrated analysis of thematic studies on hydrography, climatic aspects, geology and soils, geomorphology and erosive processes, land use and occupation, vegetation cover, demographic and socioeconomic analysis, and fauna and flora survey. In addition to the cited documents, educational material was developed for teachers to use the region's environmental context for the teaching of Geography and Sciences in primary education. The aforementioned analyzes resulted in the proposal of a geoenvironmental zoning, indicating five zones according to their natural peculiarities, having as fundamental criteria the vegetation cover/use of the land, the soils, the rocks, and the relief, being: Environmental Protection Zone ZPA), Zone of Ecological Interest (ZIE), Zone of Hydrological Interest (ZIH), Zone of Productive Restriction 1 (ZRP 1) and Zone of Productive Adequacy 2 (ZAP 2). The proposed zoning, together with the thematic studies carried out, aim to subsidize subsequent studies and assist in the discussions and decision making on sustainable environmental management within the APA-BHRM board and of the other entities that work in the unit. Also, it is expected that this study will be one of the bases for the future complementation of studies related to the management plan.
\end{abstract}

Keywords: geoenvironmental zoning, environmental management plan, conservation unit. 


\section{INTRODUÇÃO}

A Área de Proteção Ambiental da Bacia hidrográfica do Rio Machado (APA-BHRM) constitui uma Unidade de Conservação Estadual classificada na categoria de uso sustentável (Lei Federal 8895/2000). Criada pela Lei no 13.373 de 30 de novembro de 1999, a unidade de conservação (U.C.) teve sua implantação efetiva a partir de outubro de 2014, estando atribuída sua competência ao Instituto Estadual de Florestas (IEF) do estado de Minas Gerais, este vinculado à Secretaria de Estado de Meio Ambiente (SEMAD).

A APA foi criada com objetivo principal de auxiliar no uso sustentável, com ações de preservação, conservação e recuperação da bacia hidrográfica Rio Machado e seus afluentes, estimulo à proteção da fauna e flora especialmente nos ecossistemas ribeirinhos e nas áreas de preservação permanente. A UC abrange em sua maioria propriedades privadas, onde são permitidos o uso direto de seus recursos naturais, conforme previsto na legislação ambiental. Desta forma, considera-se que a gestão ambiental e as ações de todo território estão atribuídas a diferentes órgãos e entidades, como prefeituras, Polícia Ambiental, EMATER, IMA, EPAMIG, instituições de ensino, concessionárias de saneamento, entre outros.

A fim de divulgar a existência da APA-BHRM, suas principais diretrizes e mobilizar a comunidade em prol do uso sustentável da unidade, fora realizado na Câmara Municipal de MachadoMG em junho de 2015 uma reunião pública, organizada pelo IEF e Coordenadoria Regional das Promotorias de Justica do Meio Ambiente da Bacia do Rio Grande - CRRG. Nesta oportunidade também ficou estabelecido a demanda em formar o conselho da APA-BHRM. Outra pauta discutida foi a possibilidade de estabelecer parcerias, principalmente para o levantamento de dados da unidade, visando contribuir para elaboração de um Plano de Manejo compartilhado e participativo.

O desdobramento da reunião acima citada culminou em reuniões técnicas entre o IEF Regional Sul e de docentes do ICN - Instituto de Ciências da Natureza (Cursos de Geografia e Ciências Biológicas) da UNIFAL-MG (Universidade Federal de Alfenas-MG), com o intuito de discutir as possibilidades de estabelecer parceria para a realização de estudos geoambientais no âmbito da unidade. As reuniões resultaram na definição de diretrizes técnicas e financeiras para o desenvolvimento de projeto para analisar os aspectos do meio físico, socioeconômico e ambiental, com o intuito de gerar um zoneamento com indicações de áreas que apresentem o interesse na conservação.

Tendo como base as decisões tomadas na reunião pública, que foram as balizas para as reuniões técnicas posteriores, se estabeleceu uma parceria entre IEF - Machado, UNIFAL-MG e a ARPA Rio Grande - Agência Regional de Proteção Ambiental da Bacia do Rio Grande, sendo realizada entre os meses de maio de 2017 e abril de 2019, objetivando elaborar o diagnóstico 
geoambiental da APA da Bacia Hidrográfica do Rio Machado, tendo como base a análise integrada de estudos temáticos sobre hidrografia, aspectos climáticos, geologia e solos, geomorfologia e processos erosivos, uso e ocupação da terra e cobertura vegetal, análise demográfica e socioeconômica e levantamento da fauna e flora, nos limites da APA-BHRM. Além dos documentos citados, produziu-se um material didático voltado para professores utilizarem o contexto ambiental da região para o ensino de Geografia e Ciências na educação básica.

As análises mencionadas acima, resultaram na proposição de um zoneamento geoambiental, que juntamente com os estudos temáticos realizados, visam subsidiar estudos subsequentes e auxiliar nas discussões e tomada de decisões sobre a gestão ambiental sustentável no âmbito do conselho APA-BHRM e das demais entidades que atuam na unidade. Além disso, espera-se que este estudo seja uma das bases para a complementação futura dos estudos relacionados ao plano de manejo da APA-BHRM.

\section{COOPERAÇÃO TÉCNICO-FINANCEIRA}

A parceria foi estruturada a partir de firmamento de convênio de cooperação técnica e financeira entre FACEPE - Fundação de Apoio à Cultura, Ensino, Pesquisa e Extensão de Alfenas, (instituição vinculada à Universidade Federal de Alfenas - UNIFAL-MG) e a ARPA - Agência Regional de Proteção Ambiental da Bacia do Rio Grande e o IEF - Instituto Estadual de Floresta (Regional Sul),

Nos termos da parceria a UNIFAL-MG através da FACEPE se responsabilizou pelas análises técnicas a partir do envolvimento de pesquisadores, alunos de graduação e mestrado do Instituto de Ciências da Natureza (Curso de Geografia e Ciências Biológicas). A ARPA disponibilizou recursos financeiros para a compra de equipamentos, custeio de bolsas de graduação e demais despesas. O IEF - Regional Sul (Escritório de Machado-MG) auxiliou nos deslocamentos e na logística das atividades de campo, bem como nos procedimentos de autorização para os levantamentos de fauna e flora nas propriedades da unidade.

Considerando o envolvimento da equipe executiva (UNIFAL-MG e IEF) o projeto teve a participação de 12 professores, 7 bolsistas de graduação, 24 alunos de graduação voluntários e 1 aluna de mestrado, conforme descrito na tabela abaixo (Tabela 1).

A equipe foi definida a partir de reuniões técnicas realizadas com docentes do Instituto de Ciências da Natureza/UNIFAL-MG para discutir o escopo da proposta, considerando a participação voluntária dos pesquisadores. Após o firmamento da parceria, os docentes elaboram os projetos conceituais de cada área, visando produzir estudos no âmbito do diagnóstico e produção do zoneamento geoambiental. 
Tabela 1 - Áreas de análise e equipe técnica.

\begin{tabular}{|c|c|}
\hline \multicolumn{2}{|c|}{ Área de Geoprocessamento } \\
\hline Prof. Dr. Rodrigo José Pissani & Docente \\
\hline Viviane Costa Bueno & Bolsista de Graduação - Curso de Geografia \\
\hline Joice dos Reis Fiúza & \multirow{2}{*}{ Voluntário Permanente - Curso de Geografia } \\
\hline Paulo Vitor Moraes Estella & \\
\hline \multicolumn{2}{|c|}{ Área de Geomorfologia } \\
\hline Profa. Dra. Marta Felícia Marujo Ferreira & Docente \\
\hline Débora Haller da Silva Gregório & Bolsista de Graduação - Curso de Geografia \\
\hline Beatriz Liara da Cruz & \multirow{4}{*}{ Voluntário Permanente - Curso de Geografia } \\
\hline Gustavo Sousa Marinho & \\
\hline Deivison Samuel Pereira de Alfenas & \\
\hline Guilherme Silva Pinto & \\
\hline \multicolumn{2}{|c|}{ Área de Geologia e Pedologia } \\
\hline Prof. Dr. Lineo Aparecido Gaspar & Docente \\
\hline Caio Faria Cunha Barb. Adorno & Bolsista de Graduação - Curso de Geografia \\
\hline Luiz Carlos Santos Junior & \multirow{2}{*}{ Voluntário Permanente - Curso de Geografia } \\
\hline Marcius Vinicius Ver Valen C. & \\
\hline \multicolumn{2}{|c|}{ Área de Recursos Hídricos e Climatologia } \\
\hline Prof. Dr. Marcelo de Oliveira Latuf & \multirow{2}{*}{ Docentes } \\
\hline Prof. Dr. Paulo Henrique de Souza & \\
\hline Hanna Sayuri de Souza Chinen & Bolsista de Graduação - Curso de Geografia \\
\hline Pedro Henrique Silva Carvalho & \multirow{3}{*}{ Voluntário Permanente - Curso de Geografia } \\
\hline Denis Giovanni Musselli & \\
\hline Leonardo D'Olivo Margoto & \\
\hline \multicolumn{2}{|c|}{ Área de Dinâmica Socioeconômica e Demográfica } \\
\hline Prof. Dr. Flamarion Dutra Alves & \multirow{3}{*}{ Docentes } \\
\hline Prof. Dr. Gil Porto & \\
\hline Prof. Dr. Daniel Bando & \\
\hline Tiago Marini Ribeiro & Bolsista de Graduação - Curso de Geografia \\
\hline Matheus de Oliveira Silva & Voluntário Permanente - Curso de Geografia \\
\hline \multicolumn{2}{|c|}{ Área Pedagógica } \\
\hline Prof $^{\mathrm{a}}$ Dr $^{\mathrm{a}}$ Sandra de Castro de Azevedo & Docente \\
\hline \multicolumn{2}{|c|}{ Área de Fauna e Flora } \\
\hline Prof. Dr. Vinicius Xavier da Silva & \multirow[b]{3}{*}{ Docentes } \\
\hline Prof. Dr. Rogério Grassetto Teixeira da Cunha & \\
\hline Profa. Dra. Marina Wolowski Torres & \\
\hline Paulo Fernando Carlstrom & \multirow{2}{*}{$\begin{array}{l}\text { Bolsistas de Graduação - Curso de Ciências } \\
\text { Biológicas }\end{array}$} \\
\hline Maria Eduarda de Amorim Corrêa & \\
\hline Nathalia Nogueira de Ávila & $\begin{array}{l}\text { Voluntário Permanente - Curso de Ciências } \\
\text { Biológicas }\end{array}$ \\
\hline Geanne Conceição de Souza & $\begin{array}{l}\text { Voluntária - Aluna de Mestrado em Ciências } \\
\text { Ambientais }\end{array}$ \\
\hline Gleicon Velozo da Silva & \\
\hline
\end{tabular}




\begin{tabular}{|c|c|}
\hline Marcos Felipe M. Terra & \multirow{10}{*}{$\begin{array}{l}\text { Colaboradores em Atividades de Campo - } \\
\text { Graduação e Pós-graduação }\end{array}$} \\
\hline Ricardo Alves Siqueira Junior & \\
\hline Sarah Mendonça & \\
\hline Vanessa Marques de Silva & \\
\hline Matheus Raddi R. Moreira & \\
\hline Giovanna Vilas B. G. de Oliveira & \\
\hline Natalia Monique de O. Pastor & \\
\hline Rafaela Caroline dos S. Pereira & \\
\hline Leonardo Lino & \\
\hline Karine Aparecida de Lima & \\
\hline \multicolumn{2}{|c|}{ Equipe - IEF } \\
\hline Pedro Sousa Silva de Paula Ribeiro & $\begin{array}{l}\text { Engenheiro Florestal (Gerente da APA Rio } \\
\text { Machado - IEF) }\end{array}$ \\
\hline Fernando Aryson Milan & $\begin{array}{l}\text { Gestor Ambiental (Monitor Ambiental da APA } \\
\text { Rio Machado - MGS) }\end{array}$ \\
\hline Nádia Alvim Pereira & $\begin{array}{l}\text { Secretária da APA Rio Machado (Prefeitura de } \\
\text { Machado/MG) }\end{array}$ \\
\hline Amilton Ferri Vasconcelos & Engenheiro Agrônomo (Regional Sul - IEF) \\
\hline Rodrigo Martins Goulart & Engenheiro Florestal (Regional Sul - IEF) \\
\hline Danielle de Assis Andery & Médica Veterinária (Regional Sul - IEF) \\
\hline Cássio de Sousa Borges & Biólogo (Regional Sul - IEF) \\
\hline Paulo Roberto de Laura & Engenheiro Florestal (Núcleo de Lavras - IEF) \\
\hline Benedito Edmilson Ferraz & $\begin{array}{l}\text { Engenheiro Florestal (Núcleo de Poços de } \\
\text { Caldas - IEF) }\end{array}$ \\
\hline Ronaldo Carvalho de Figueiredo & Direito (Regional Sul - IEF) \\
\hline Anderson Ramiro Siqueira & Direito (Regional Sul - IEF) \\
\hline
\end{tabular}

\section{3. ÁREA DE ESTUDO}

A APA - BHRM está localizada no sul do estado de Minas Gerais compreendendo uma área de 101600 ha, delimitada pela própria bacia hidrográfica do Rio Machado, que abrange 11 municípios: Alfenas, Machado, Paraguaçu, Fama, São João da Mata, Poço Fundo, Carvalhópolis, Espirito Santo Dourado, Ipuíuna, Campestre e Santa Rita de Caldas (Figura 1).

A Bacia hidrográfica do Rio Machado apresenta predomínio do Bioma Mata Atlântica (floresta ombrófila densa, estacional semidecidual, charcos de brejos e campos de altitude) e transição para Cerrado (cerradão) ao norte.

Com diferentes fitofisionomias, apresenta também riqueza de espécies silvestres, como alguns animais vulneráveis ou ameaçados de extinção: onça parda, lobo guará, jaguatirica bugio, e outros. Possui uma flora diversificada com espécies arbóreas representadas pela massaranduba, jequitibá, jacarandá, canela sassafrás, óleo vermelho, barba timão, etc.. 


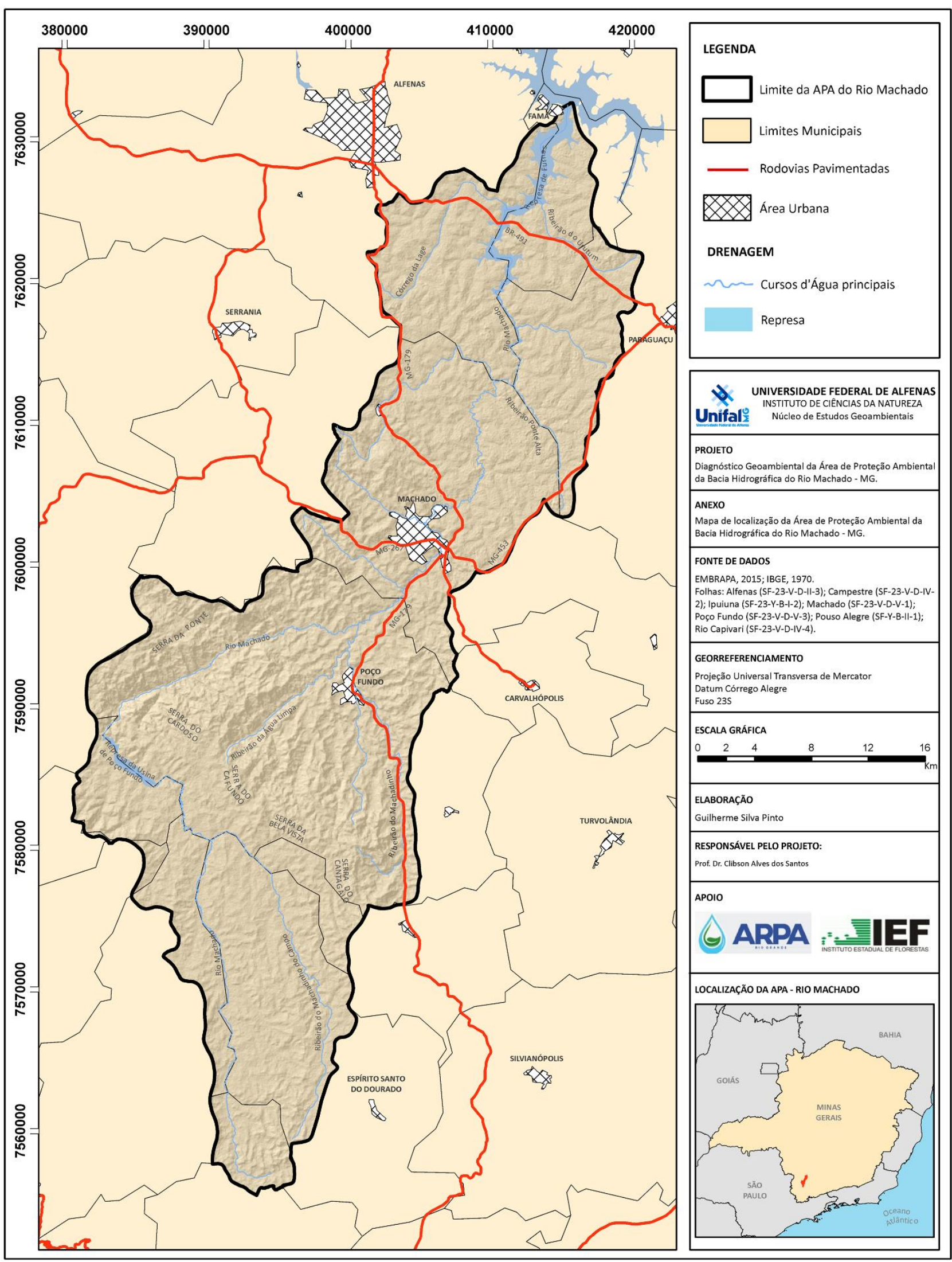

Figura 1 - Localização da APA da Bacia Hidrográfica do Rio Machado. 
Predomina como atividade econômica as práticas agrossilvipastoril, com a presença de plantios anuais e perenes, como café, milho, morango, mandioquinha, batata, fumo, hortaliças e outras dependendo da região da Unidade e vocação das comunidades ali inseridas. Verifica ainda a silvicultura de eucalipto e a pecuária de corte e leite. Destaca algumas espécies florestais nativas com aproveitamento econômico, como o Marolo em Paraguaçu. Também está representado por atividades industriais e o comércio em geral. Atividades turísticas também são verificadas na APA, embora sem planejamento ou ordenamento de visitantes, como na Cachoeira da Barragem (Poço Fundo), Pedra do Navio (São João da Mata), pesca esportiva na represa em Fama e outros.

Entre os principiais vetores de pressão e causadores de impactos negativos, estão o crescimento das cidades sobre áreas nativas, a mineração e dragagem de areia no leito do Rio Machado, uso intensivo de agrotóxico, parcelamento do solo rural, desmatamento de sub-bosque, atropelamento da fauna nas rodovias que passam no interior da Unidade e o uso do fogo sem autorização.

Nesse sentido, a realização do presente estudo será de fundamental importância nas ações efetivas de conservação da APA e no planejamento de estratégias preservação e prevenção referente aos problemas observados na Unidade.

\section{MÉTODOS E TÉCNICAS}

O presente estudo foi realizado entre os meses de junho de 2017 e abril de 2019, visando realizar análises dos componentes do meio físico-biótico para propor o zoneamento geoambiental da APA-BHRM, resultante de uma compreensão integrada dos aspectos geológicos, geomorfológicos, pedológicos, hidrográficos, climatológicos, florísticos, faunísticos, problemas ambientais, uso e ocupação da terra, e socioeconômicos. Essas análises, bem como o zoneamento geoambiental auxiliará na definição de diretrizes de planejamento espacial e na elaboração de estudos de prognósticos e tomada de decisões no âmbito da unidade.

A metodologia empregada nesse projeto para a indicação do zoneamento geoambiental teve como base a concepção de análise integrada definida nos pressupostos da análise geossistêmica, tendo como base o pensamento de Tricart (1977) sobre o comportamento dinâmico da paisagem, suas as trocas de fluxo de energia e matéria nos componentes do meio físico-biótico. Essas prerrogativas se constituem na base metodológica indicadas para a elaboração do Zoneamento Ecológico-Econômico, considerado um dos principais instrumentos de planejamento ambiental territorial do Brasil. Vários são os estudos discutindo a análise geossistêmica, como indicando formas de aplicação em estudos sobre a dinâmica dos ambientes, tais como Tricart (1977), Christofoletti (2002), Ross (1992;1994), Crepani (2001), Sporl (2007), Rosolém \& Archela (2010), GUERRA, et. al. (2012), entre outros. 
As análises dos diversos componentes do meio natural indicadas acima foram desenvolvidas por meio de metodologias específicas de cada área, utilizando-se de análises e levantamentos de dados secundários e primários, realizados em órgão oficiais, entrevistas, análises de campo e nos laboratórios do Instituto de Ciências da Natureza (Lab. de Geoprocessamento e Cartografia, Lab. de Geomorfologia e Análise Ambiental, Lab. de Geociências e Lab. Estudos Rurais e Urbanos) da UNIFAL-MG.

No entanto, o desenvolvimento do estudo como um todo teve que seguir um fluxo de trabalho, visando cumprir os pressupostos indicados no plano de trabalho definido nos termos da parceria. Com isso, o projeto foi desenvolvido ao longo de quatro principais fases, conforme será mostrado a seguir.

\subsection{Levantamento e Organização de Dados Básicos}

Inicialmente as atividades foram destinadas para o levantamento de dados secundários, abordando os aspectos teóricos - metodológicos sobre a temática analisada e os aspectos do meio físico e social da região. Nesse mesmo período foi realizado o levantamento cartográfico, buscando a aquisição de mapas e cartas temáticas e básicas já elaboradas, além de imagens de satélite, ortofotos e aerofotos disponíveis. Essa sequência de análise foi seguida por todas as áreas, porém o tempo de realização teve variações, devido as especifidades dos temas analisados.

No início das atividades foram realizadas reuniões técnicas para discutir questões comuns a todas as áreas, tais como as escalas de análises a serem usadas e o nível de abordagem dos levantamentos primários, sendo reafirmado que os estudos seriam realizados em níveis de detalhamento compatíveis com as cartas topográficas disponibilizadas pelo IBGE na escala de 1:50.000, conforme previsto na proposta. No entanto, nos levantamentos de fauna e flora optou-se ainda por análises nos fragmentos florestais, devido a falta de registros bibliográficos realizados nos limites da unidade de conservação.

Com as informações levantadas, priorizou a compilação dos produtos cartográfico, resultando nos seguintes mapas temáticos: geológico, geomorfológico regional, pedológico, rede hidrográfica, hipsométrico, declividade, cobertura vegetal e uso da terra. Esse material será elaborado sobre a base cartográfica do trabalho, digitalizada e georreferenciada. Após coleta e análise das referências bibliográficas e elaboração dos produtos cartográficos acima citados, serão realizados trabalhos de campo para verificação, correção e validação dos dados. 


\subsection{Atividades de Campo}

As atividades de campo foram iniciadas no segundo mês do projeto, se estendendo por quase todo o restante do trabalho, sendo em alguns momentos concomitante com as demais atividades. As análises de campo consistiram na verificação e complementação dos mapas temáticos elaborados na etapa anterior, bem como no levantamento de dados primários relacionados ao meio físico, socioeconômico e biológico.

No total foram realizadas 41 campanhas de campo, percorrendo aproximadamente 9.179 quilômetros nos limites da APA-BHRM, para a coleta de dados socioeconômicos e demográficos com a comunidade rural, identificação de problemas ambientais (processos erosivos), controle de campo do mapeamento do uso da terra e cobertura vegetal, análise dos aspectos geomorfológicos, geológicos (litologia e recursos minerais) e levantamento da geodiversidade (geossítios), coleta de amostras de solo e o registro, coleta e monitoramento de espécies da fauna e flora em fragmentos florestais pré-selecionados pela equipe responsável por essa análise e o IEF.

\subsection{Interpretação e Correlação dos Dados}

Essa fase corresponde à análise dos resultados obtidos a partir dos levantamentos realizados em gabinete, laboratório e os dados obtidos em campo. Conforme ressaltado acima, cada área seguiu metodologias e cronograma diferente, devido às suas especificidades, porém a sequência segue a mesma.

As análises obtidas tanto dos levantamentos de dados primários como secundários, subsidiaram a compreensão das características dos componentes do meio físico-biológico, bem como do perfil socioeconômico da unidade de conservação. Nessa fase cada área descreveu e interpretou os fenômenos e processos naturais e socioeconômicos observados, prezando em compreendê-los do ponto de vista da sua dinâmica para auxiliar na identificação de vulnerabilidades naturais da área. Com isso, os resultados apresentaram informações qualitativas e quantitativas que possibilitaram a correlação entre as diversas áreas, para a indicação o zoneamento geoambiental.

\subsection{Elaboração dos Produtos Finais}

Essa etapa consistiu, principalmente na elaboração dos produtos e análises de cada área, resultando num relatório final temático descrevendo os aspectos regionais e as características locais nos limites da unidade, bem como análises que auxiliassem na identificação de fragilidades naturais da área. Além disso, os relatórios abordaram aspectos que poderiam auxiliam na indicação/particularização de zonas que mereciam recomendações específicas para o uso sustentável 
e desenvolvimento de atividades de uso da terra e/ou apropriação dos recursos naturais existentes na APA-BHRM.

Como produtos finais foram elaborados para a área de estudo os seguintes mapas e análises:

- Análise demográfica e aspectos Socioeconômicos;

- Mapa compartimentos geomorfológicos;

- Mapa Morfodinâmico (processos erosivos e movimentos de massa);

- Mapa Geológico;

- Mapa Pedológico;

- Mapa de Geodiversidade;

- Mapa de Cobertura Vegetal e Uso da Terra;

- Inventários de Fauna e Flora.

A partir da compreensão integrada dos aspectos do meio físico-biótico descritos através dos produtos acima citados, procedeu-se a elaboração da proposta de zoneamento geoambiental, que sera mostrado no tópico a seguir.

Além dos produtos acima citados, produziu-se ainda um Material Pedagógico sugerindo atividades as quais os professores de Geografia e Ciências possam usar no ensino fundamental e médio para discutir temas relacionados a conceitos básicos e aplicados relacionados a cartografia, meio físico e a conservação ambiental, tendo como base as informações e dados da APA - BHRM. Esse material é de extrema relevância para que os estudantes possam conhecer os aspectos locais, bem como aplicar à sua realidade os conteúdos ministrados em sala e auxiliar no processo de proteção e conservação ambiental.

As principais análises e resultados das pesquisas acima citadas estão sumarizadas nos artigos científicos publicados na presente edição especial da Revista Caderno de Geografia.

\section{ZONEAMENTO GEOAMBIENTAL DA APA-BHRM}

O zoneamento geoambiental deve resultar na particularização de unidades territoriais ou zonas com características geo-bio-físicas similares, de forma que seja possível compreender a dinâmica da paisagem, bem como auxiliar no ordenamento territorial da área, relacionados ao uso e ocupação da terra de forma sustentável.

Santos (2004) relata que o zoneamento não deve ser apenas um parcelamento do espaço com o intuito de estabelecer ou orientar sobre os usos permitidos, mas deve estar comprometido com políticas de desenvolvimento pré-estabelecidas, fundamentadas no uso sustentável e nas diretrizes 
concretas para a sua aplicação. Com isso, os estudos de localização de empreendimentos ou atividades econômicas estarão inseridos no contexto da gestão ambiental, que terá, nas análises realizadas através do zoneamento, uma importante ferramenta acerca da viabilidade ambiental da atividade a ser implementada.

A compartimentação geoambiental aqui proposta foi realizada a partir da sobreposição dos mapas de compartimentação geomorfológica, morfodinâmico, geológico, pedológico, cobertura vegetal uso e ocupação da terra e de fragmentos florestais. Devido a escala de análise e as características da área foram realizadas adequações para se definir as unidades. Apesar de convencionalmente as nomenclaturas de zoneamentos geoambientais fazerem referência a unidades geológico-geomorfológica, nesse estudo as zonas são nomeadas indicando o perfil de uso da terra e de conservação ambiental, haja vista que o propósito dessa pesquisa é subsidiar as discussões sobre o uso sustentável na unidade de conservação.

Diante disso, foram definidas cinco zonas segundo as suas peculiaridades naturais, tendo como critérios fundamentais a cobertura vegetal/uso dos terrenos, os solos, as rochas e o relevo (Figura 2), sendo elas: Zona Proteção Ambiental (ZPA), Zona de Interesse Ecológico (ZIE), Zona de Interesse Hidrológico (ZIH), Zona Restrição Produtiva 1 (ZRP 1) e a Zona de Adequação Produtiva 2 (ZAP 2).

\subsection{Descrição das Unidade Geoambientais}

\subsubsection{ZAP - Zona Proteção Ambiental}

As zonas de proteção ambiental representam os fragmentos florestais analisados no âmbito do projeto, representados por remanescentes de mata atlântica na porção centro-sul da bacia e por zonas de transição e cerrados na porção norte da unidade (Figura 3).

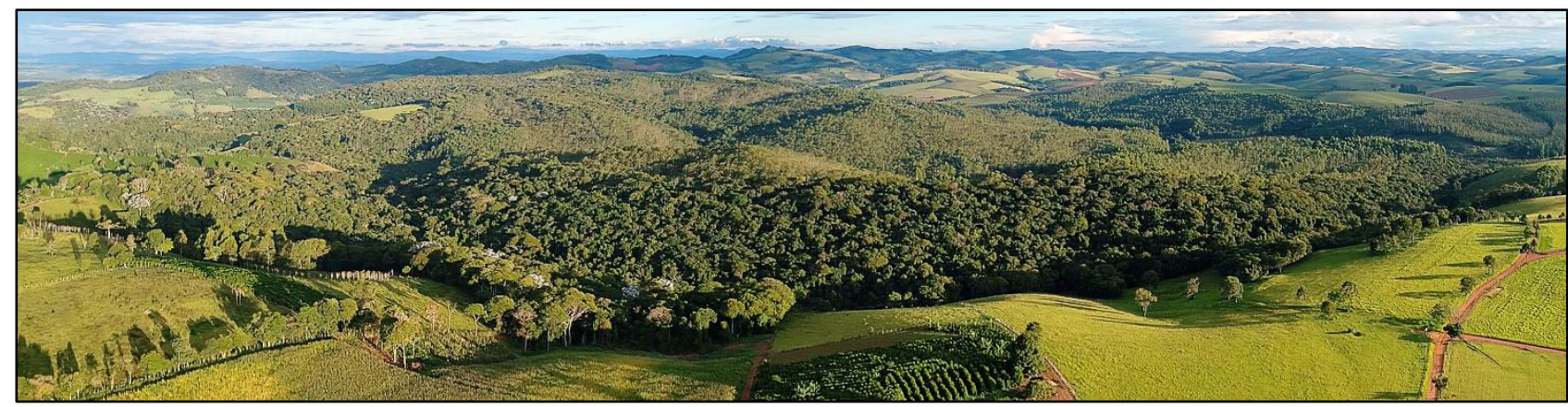

Figura 3 - Fragmento florestal Bela Vista, remanescente de Mata Atlântica na zona ZPA - Zona de Proteção Ambiental. Foto: Clibson Alves dos Santos, Fevereiro de 2019. 
Os levantamentos de fauna e flora realizados mostram que essas áreas apresentam uma grande fragilidade por abrigar espécies exóticas e ameaçadas de extinção, considerarmos as listas brasileira e mineira de espécies ameaçadas. Outro aspecto relevante dessas são as possibilidades de serem núcleos de ligação de corredores ecológicos e conservação das margens do canal principal do Rio Machado nas proximidades da Rodovia MG 491 (Figura 4).

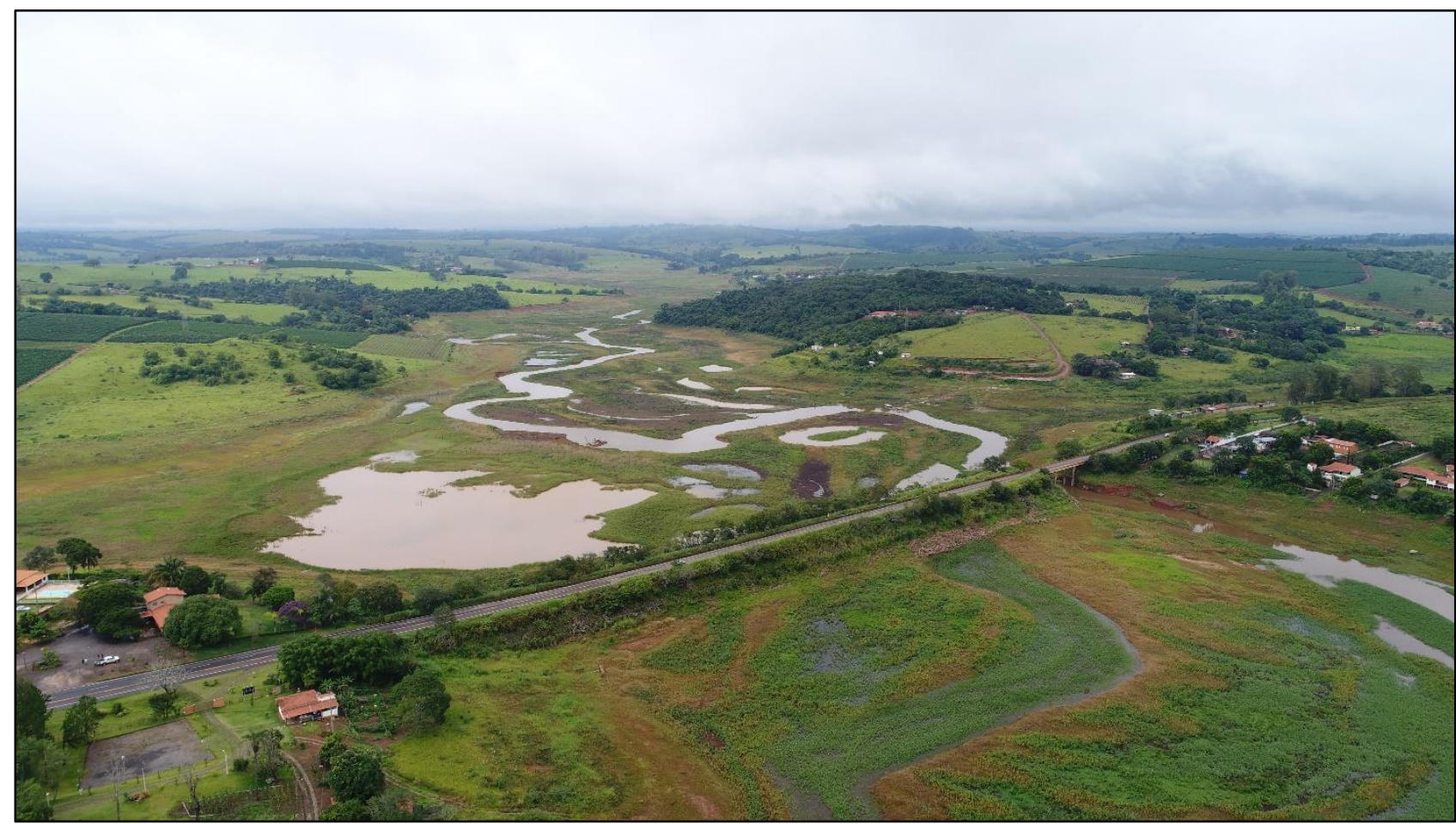

Figura 4 - Fragmento florestal às margens do Rio Machado nas proximidades da Rodovia MG 491. Foto: Clibson Alves dos Santos, Junho de 2018.

Além disso, o entorno dos fragmentos sofre pressão de atividades silvo-agro-pastoril, evidenciando a importância de estabelecer regras protetivas. Salienta-se ainda, que levantamentos posteriores devem ser feitos para identificar outros remanescentes de mata nativa existentes na área. 


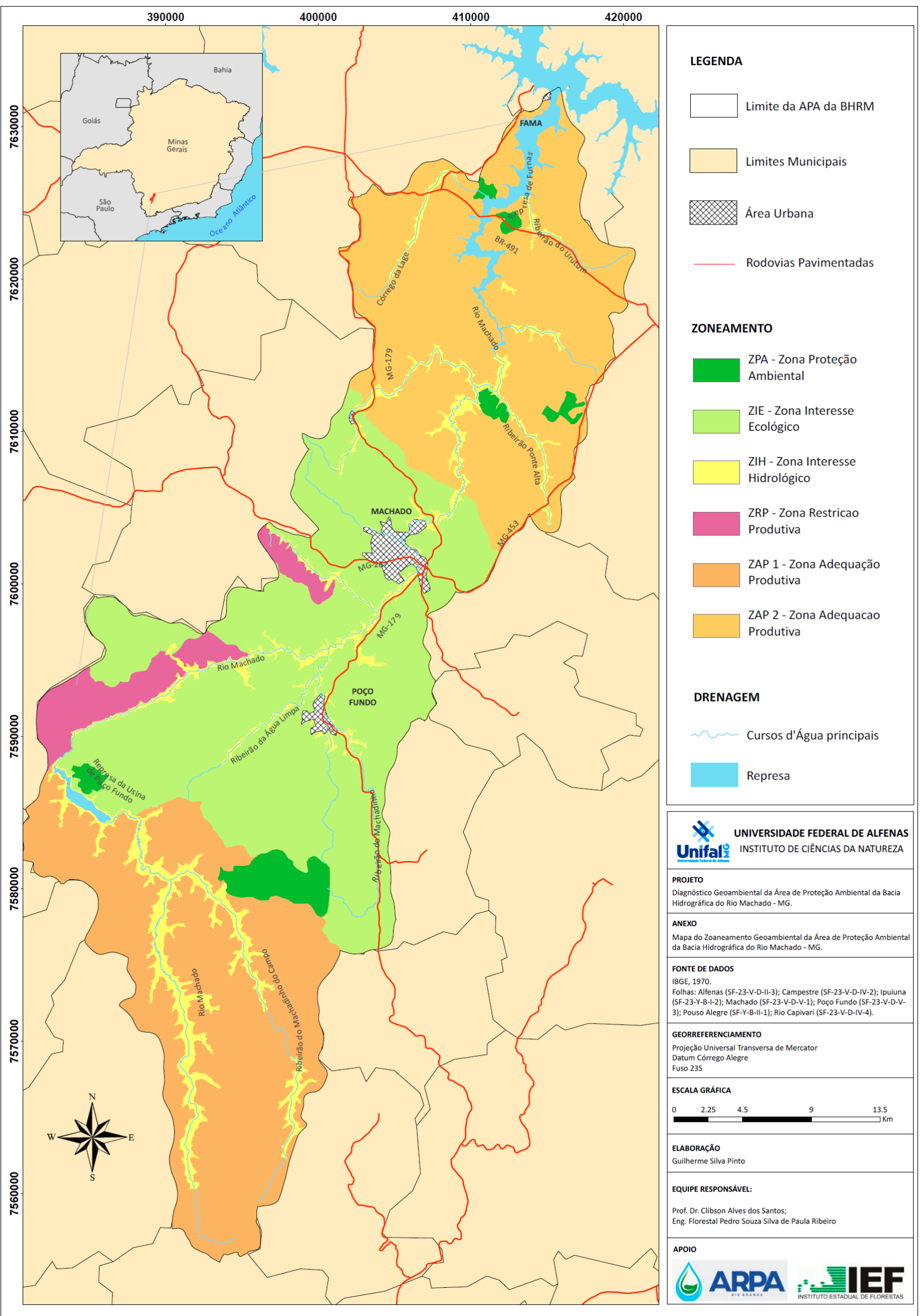

Figura 2 - Zoneamento geoambiental da APA da Bacia Hidrográfica do Rio Machado. 


\subsubsection{ZIE - Zona Interesse Ecológico}

As unidades de interesse ecológico correspondem a porção central da bacia, sendo observadas as feições de mata nativa e cultivos de ciclo longo, como as plantações de café nas encostas (Figura 5).

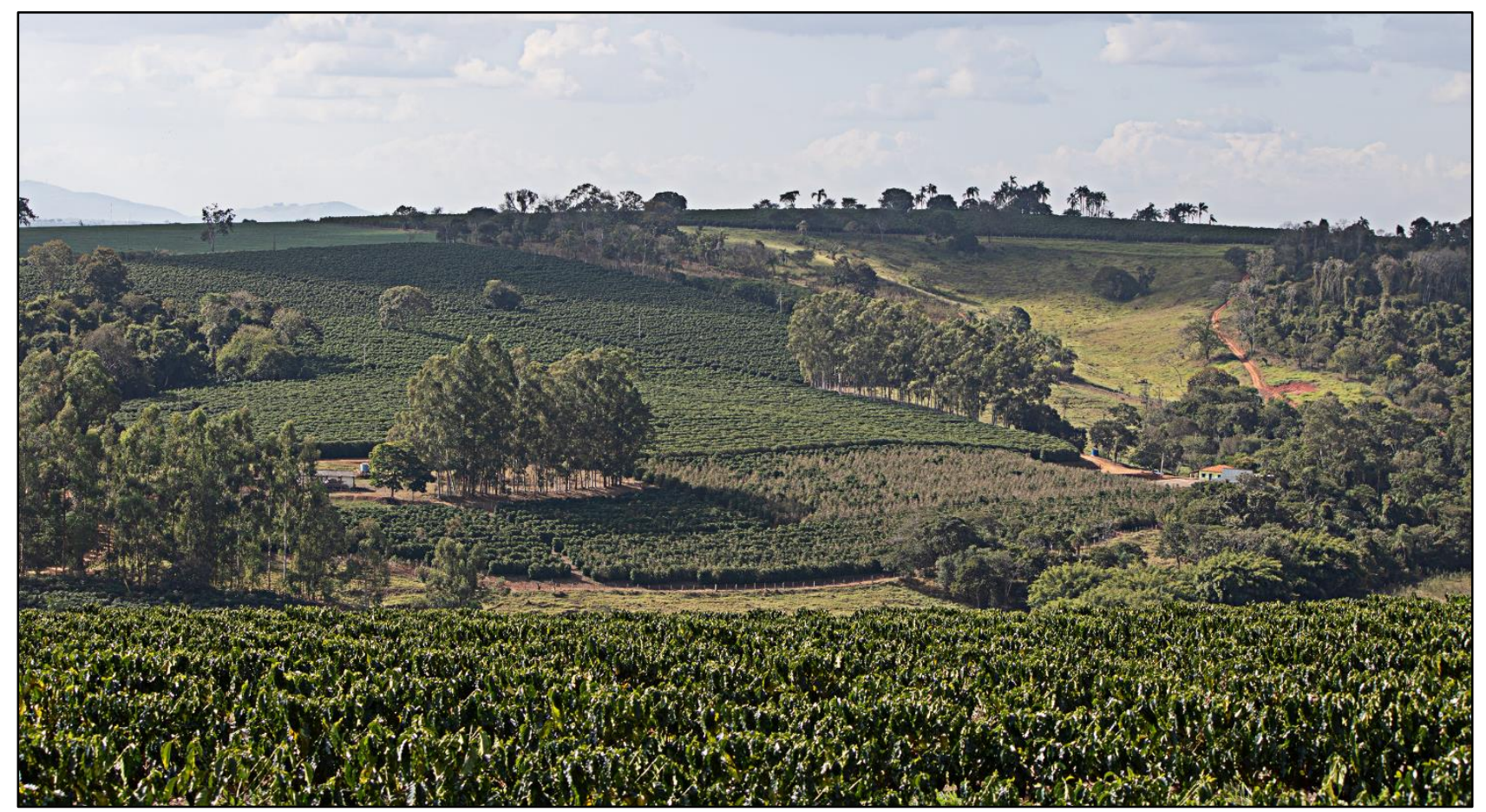

Figura 5 - Plantios de café, intercalados com cultivos de milho nos morros de encostas suaves na zona de Interesse Ecológico. Foto - Clibson Alves dos Santos, Junho de 2019.

A morfologia dos terrenos corresponde principalmente a morros e colinas com declives suaves, favorecendo o desenvolvimento da agricultura cafeeira, que se intercala em menor escala com plantios de ciclo curto (milho) e os remanescentes florestais, em zonas de transição entre Mata Atlântica e Cerrados. Quando ocorre de maneira equilibrada, essas culturas favorecem a proteção do ambiente, bem como auxilia o equilíbrio ecológico da área. No entanto, são observados na unidade processos erosivos laminares, em forma de sulcos e voçorocas, resultantes do mal uso do solo, principalmente em áreas de pastagem (Figura 6).

Com isso, as atividades devem priorizar o sistema agroflorestal, aliando o consorcio entre os cultivos com a floresta, protegendo os remanescentes florestais e conservando o solo. No entanto, salienta-se que no Art. $4^{\circ}$ da DN COPAM no 73 (MINAS GERAIS, 2004) proíbe o corte, a exploração e a supressão de vegetação primária ou nos estágios avançado e médio de regeneração da Mata Atlântica, em áreas rurais e urbanas no estado de Minas Gerais. 


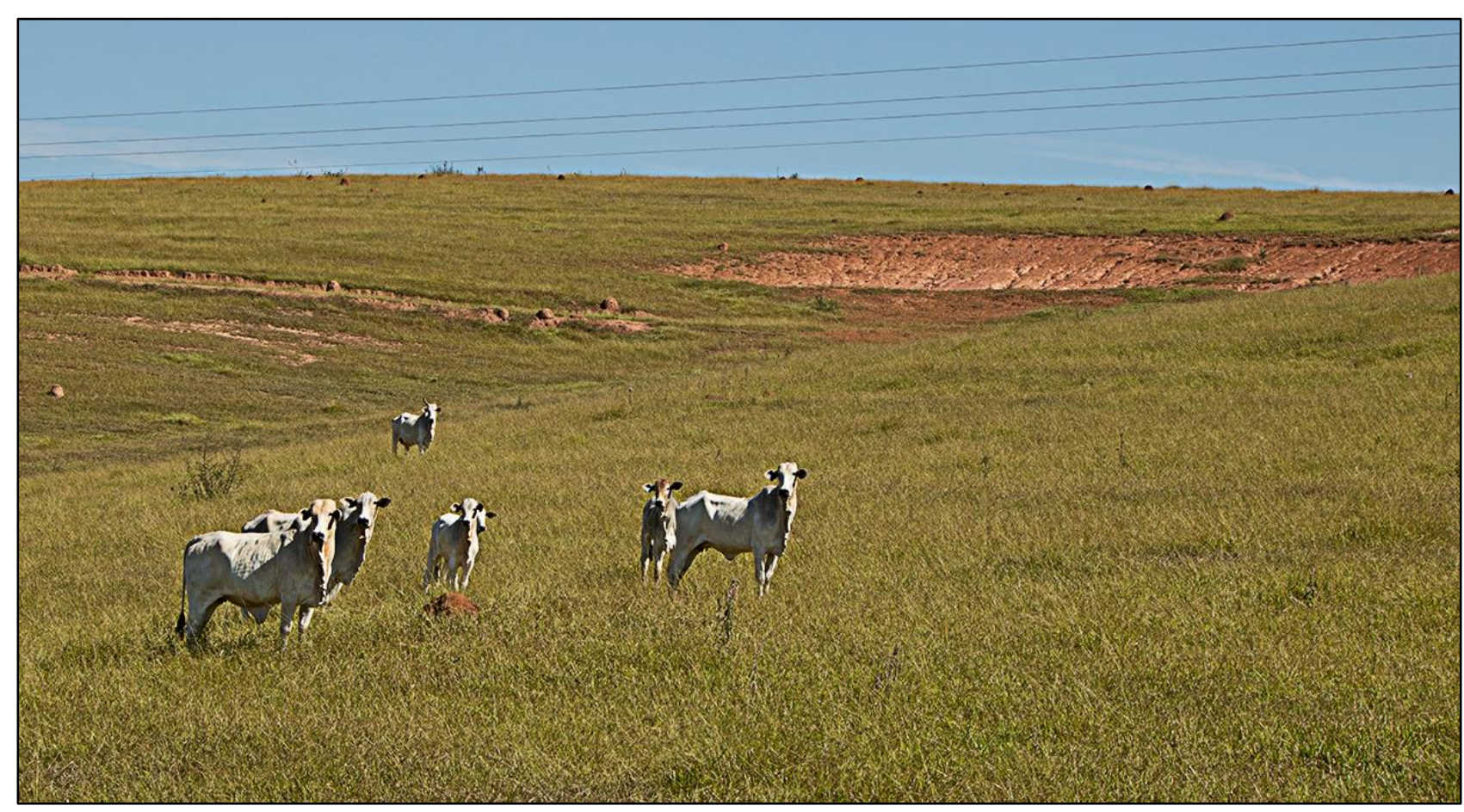

Figura 6 - Erosão laminar e em sulcos em áreas de pastagem na Zona de Interesse Ecológico. Foto - Clibson Alves dos Santos, Junho de 2018.

Ressalta-se ainda a importância da conservação das áreas de preservação permanentes de topo de morros e das margens dos cursos d’água (matas ciliares) fundamentais como ambientes de recarga do lençol freático e da manutenção de nascentes, bem como na função de corredores ecológicos, ligando as porções norte e sul da bacia.

\subsubsection{ZIH - Zona Interesse Hidrológico}

As zonas de interesse hidrológico estão localizadas nas planícies de inundação e nas suas margens, são caracterizadas por serem ambientes de deposição de sedimentos e da dinâmica natural dos rios (Figura 7). Representam relevante importância hídrica, por serem os ambientes de ocorrência de nascentes que formam os corpos hídricos, bem como preservam diversos ecossistemas fluviais. Correspondem a áreas que foram formadas ao longo dos últimos milhares de anos, resultantes do processo de erosão natural ocorrido no relevo da região.

Essas áreas, bem como suas margens se constituem em áreas de preservação permanente, conforme o código florestal vigente. Atividades agropastoris em qualquer escala podem desencadear desequilíbrios da dinâmica fluvial, resultando em enchentes que podem provocar danos materiais, patrimoniais, financeiros e perdas de vidas, principalmente nas áreas urbanas e comunidades rurais, como os eventos hidrológicos historicamente observadas nos núcleos urbanos de Machado-MG e Posso Fundo-MG. Além disso, as matas ciliares observadas nessas zonas apresentam relevante importância como corredores ecológicos ao longo de toda a bacia. 


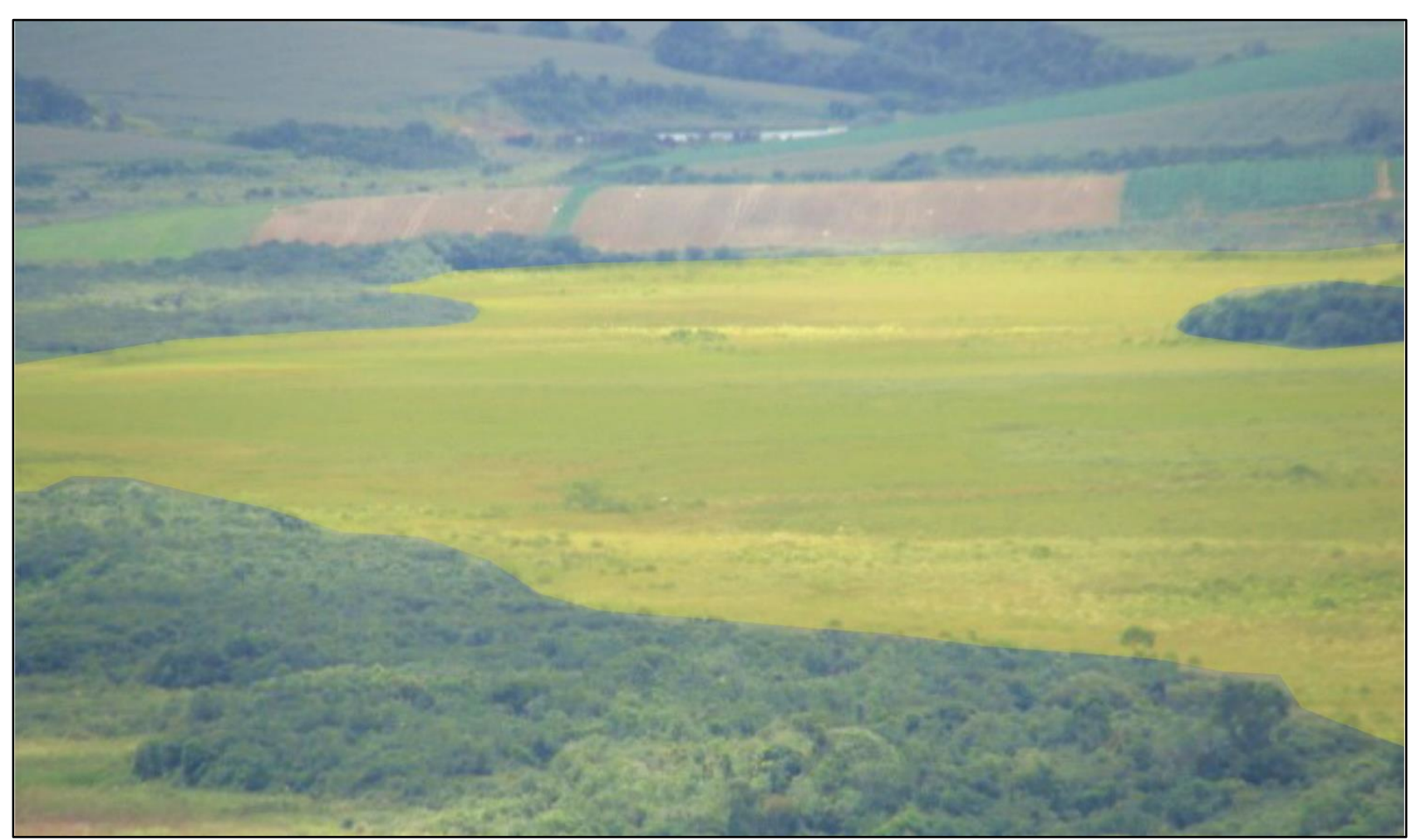

Figura 7 - Planícies de inundação (destaque em amarelo) e ambiente de acúlmulo de sedimentos, correspondentes à Zona de Interesse Hidrológico. Foto: Clibson Alves dos Santos, Junho de 2018.

\subsubsection{ZIH - Zona Restrição Produtiva}

As áreas de restrição produtiva são os ambientes de relevo acentuado, formado por morros com encostas íngremes e solos pouco desenvolvidos devido a morfologia da área (Figura 8).



Figura 8 - Plantios de café em encostas íngremes em morros, num contexto de relevo escarpado na Zona de Restrição Produtiva. Foto - Clibson Alves dos Santos, Junho de 2018. 
São observados os cultivos de altitude, principalmente as plantações de café, que se desenvolvem bem nesses ambientes e em conjunto com a mata nativa mantem o ambiente em equilíbrio (Figura 9), fazendo a função de corredores ecológicos e ligando os fundos de vales aos topos de morros.

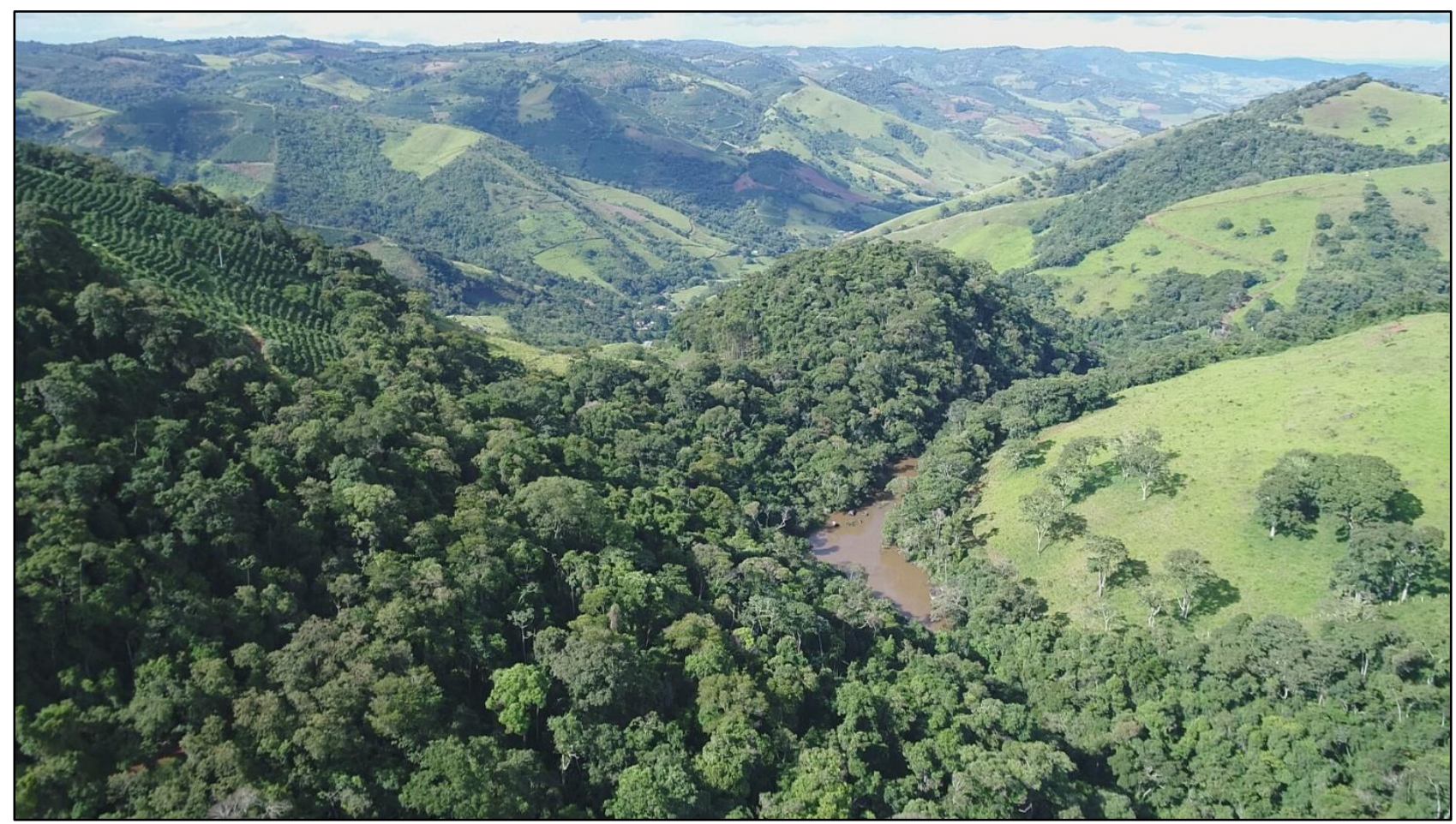

Figura 9 - Remanescentes de mata nativa ligando os fundos de vales aos topos de morros na Zona de Restrição Produtiva. Foto: Clibson Alves dos Santos, Junho de 2018.

Alterações nesse perfil de uso da terra, a ampliação dos cultivos e pastagens existentes podem desencadear processos erosivos acelerados, como as ravinas e os sulcos já observados na área

\subsubsection{ZAP 1 - Zona Adequação Produtiva}

A ZAP 1 localiza-se na porção do alto Rio Machado, onde as culturas agrícolas de ciclo curto, de frutas como as plantações de morango e as pastagens são observadas, sobre um terreno com morfologia de colinas, morros com encostas suaves e morrotes (Figura 10).

A unidade é predominantemente constituída por cambissolos, que associados a um manejo inadequado do solo pode intensificar a ocorrência e o desenvolvimento dos processos erosivos. Essa unidade apresenta a maior concentração de ravinas, voçorocas, sulcos e escorregamentos, que intensificam os processos de assoreamento dos corpos hídricos. Esses processos causam o desequilíbrio na dinâmica fluvial, intensificando a ocorrência de enchentes e inundações, alteram o equilíbrio da fauna e flora aquática, bem como na elevação dos níveis de sedimentos no reservatório da PCH - Pequena Central Hidrelétrica de Poço Fundo. Recomenda-se que as atividades agropastoris 
observadas na unidade devem ser desenvolvidas com técnicas de conservação do solo, protegendo os terrenos dos processos erosivos, que na área de estudo são resultantes do manejo inadequado do solo para uso agrícola.

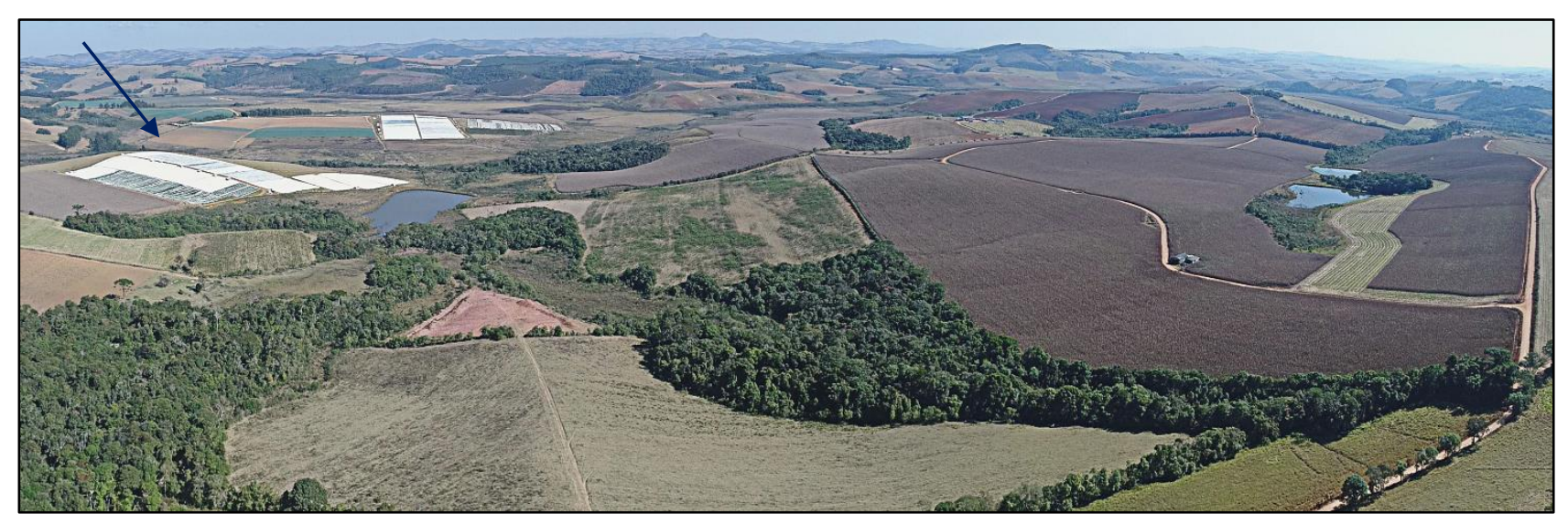

Figura 10 - Plantios de morango (seta) e culturas de ciclo curto na Zona de Adequação Produtiva 1.

Foto: Clibson Alves dos Santos, Junho de 2018.

\subsubsection{ZAP 2 - Zona Adequação Produtiva}

A ZAP 2 localiza-se porção norte da bacia, próximo da região da foz Rio Machado, que semelhante a ZAP 1 são observadas as culturas agrícolas e as pastagens, porém sobre a morfologia de encostas suaves de colinas. Nessa área é comum as culturas temporárias como a soja e o milho (Figura 11).

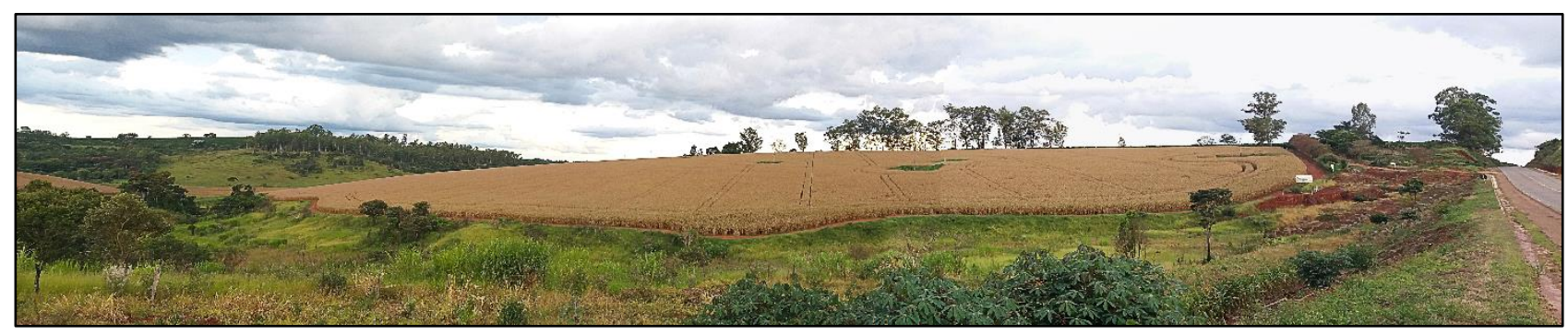

Figura 11 - Plantio de milho nas colinas da unidade ZAP 2.

Foto: Clibson Alves dos Santos, Junho de 2019.

Os solos da unidade são constituídos por latossolos distróficos, que apesar de serem desenvolvidos pedologicamente, carecem de um maior manejo o plantio, visando a correção das bases de fertilidade química. Essa zona apresenta a maior concentração de processos erosivos laminares e em forma de sulcos e ravinas. Os efeitos do mal uso solo podem intensificam os processos de assoreamento dos corpos hídricos e desequilíbrios semelhantes aos mencionados na ZAP 1, porém impactando o reservatório da Usina Hidrelétrica de Furnas. Recomenda-se que as atividades agropastoris observadas na unidade devem ser desenvolvidas com técnicas de proteção do solo. 


\section{CONSIDERAÇÕES FINAIS}

Os estudos desenvolvidos no âmbito desse diagnóstico correspondem aos levantamentos básicos relacionados meio natural e para compreensão inicial do perfil socioeconômico da área. $\mathrm{O}$ zoneamento geoambiental proposto indica unidades que poderão servir de base para detalhamentos futuros referentes a definição de zoneamento ambiental no âmbito plano de manejo, pois o que se difere da presente proposta seria um aprofundamento dos aspectos sociais, econômicos, culturais e biológicos, a participação dos agentes sociais da unidade, através da realização de oficinas de planejamento, bem como outros tópicos indicados na metodologia de elaboração dos planos. A continuidade dos estudos resultaria na definição de prognósticos, programas, projetos e ações, bem como uma discussão coletiva para a ampliação e/ou adequação do zoneamento aqui proposto.

Assim, as orientações do zoneamento ambiental do plano de manejo resultam não apenas das fragilidades e vulnerabilidades naturais da área, como também do anseio popular local. Diante disso, esse estudo se caracteriza como um primeiro passo para a elaboração do plano de manejo, fornecendo dados e análises importantes sobre as principais características do meio físico-biótico, indicando as áreas que merecem uma especial atenção sobre o desenvolvimento das atividades de uso e ocupação da terra.

A destinação proposta nas unidades deste zoneamento são orientativas e não exime de estudos quantitativos locais e da adoção dos respectivos instrumentos legais para a implementação dos empreendimentos e/ou outras análises específicas. Certo também, é que todo tipo de atividade trará algum impacto ambiental. Assim, é fundamental que estudos iguais a esses estejam inseridos num processo de gestão sustentável dos recursos naturais, pois assim, o desenvolvimento econômico estará alinhado a sustentabilidade social e ambiental da região em enfoque.

Por fim, em etapas futuras indica-se a complementação com estudos mais detalhados, bem como a discussão no âmbito do Conselho Gestor da APA-BHRM e demais órgãos competentes, de forma que um novo zoneamento territorial proposto seja participativo, juridicamente válido e reflita os interesses coletivos no tocante ao manejo sustentável da unidade de conservação.

\section{AGRADECIMENTOS}

Toda a equipe envolvida no desenvolviemnto do projeto "Diagnóstico geoambiental da APA da bacia hidrográfica do rio Machado/MG" agradece a ARPA Rio Grande pelo apoio financeiro, ao Ministério Público de Minas Gerais através da Coordenadoria Regional das Promotorias de Justica do Meio Ambiente da Bacia do Rio Grande por auxiliar no firmamento da parceria e o IEF pelo apoio logístico e técnico na realização das atividades. 


\section{REFERÊNCIAS}

CHRISTOFOLETTI, A. Modelagem de sistemas ambientais. 1. ed. São Paulo: Edgard Blucher, 2002. 236p.

CREPANI, E.; MEDEIROS, J. S.; FILHO, P. H.; FLORENZANO, T. G.; DUARTE, V.; BARBOSA, C. C. F. Sensoriamento Remoto e Geoprocessamento Aplicados ao Zoneamento EcológicoEconômico e ao Ordenamento Territorial. 1. ed. São José dos Campos: INPE, 2001. 103p.

MINAS GERAIS. Deliberação Normativa COPAM n ${ }^{\circ} 73$, de 8 de setembro de 2004. Dispõe sobre a caracterização da Mata Atlântica no Estado de Minas Gerais, as normas de utilização da vegetação nos seus domínios e dá outras providências. 2004. Disponível em: http://www.siam.mg.gov.br/sla/download.pdf?idNorma=164. Acessado em: 03 mai. 2019.

ROSS, J. L. S. O registro cartográfico dos fatos geomórficos e a questão da toxonomia do relevo. Revista do Departamento de Geografia, São Paulo, v. 6, p. 17-29, 1992.

ROSS, J. L. S. Análise empírica da fragilidade dos ambientes naturais e antropizados. Revista do Departamento de Geografia, São Paulo, v. 8, p. 63-74, 1994.

SANTOS, R. F. Planejamento ambiental: teoria e prática. 1. ed. São Paulo: Oficina de Textos, 2004. 184p.

SPORL, C. Metodologia para elaboração de modelos de fragilidade ambiental utilizando redes neurais. 2007. 185 f. Tese (Doutorado em Geografia Física) - Faculdade de Filosofia, Letras e Ciências Humanas, Universidade de São Paulo, São Paulo, 2007.

TRICART, J. Ecodinâmica. 1. Ed. Rio de Janeiro: IBGE, 1977. 97p.

Trabalho enviado em 25/05/2019

Trabalho aceito em 25/06/2019 